Article

\title{
Mutuals on the Move: Exclusion Processes in the Welfare State and the Rediscovery of Mutualism
}

\author{
Eva Vriens ${ }^{1, *}$ and Tine De Moor ${ }^{2}$ \\ ${ }^{1}$ Department of Sociology, Utrecht University, 3512 BS Utrecht, The Netherlands; E-Mail: e.vriens@uu.nl \\ ${ }^{2}$ Department of Social and Economic History, Utrecht University, 3512 BS Utrecht, The Netherlands; E-Mail: t.demoor@uu.nl \\ * Corresponding author
}

Submitted: 28 March 2019 | Accepted: 31 July 2019 | Published: 20 March 2020

\begin{abstract}
Declining welfare states and increasing privatization of the insurance sector are leaving an increasing number of people, particularly in Europe, without insurance. In many countries, new initiatives like Friendsurance (Germany), Broodfonds (the Netherlands), and Lemonade (US) have emerged to fill this gap. These initiatives, sometimes called peer-to-peer insurance, aim to make insurance fair, transparent, and social again. Resembling 19th-century mutuals, they pool premiums in (small) risk-sharing pools. We compare eleven new mutuals with respect to their institutional, resource, and member characteristics and find two broad typologies. The first bears the most resemblance to the 19th-century mutuals: Members are (partly) responsible for governance, there is no risk differentiation, premiums are fixed and low, and insurance payouts cover basic expenses only and are not guaranteed. The second group, while also applying risk-sharing and redistribution of unused premiums, is organized more like the present-day commercial insurers it reacted against, e.g., with refined InsurTech methods for risk differentiation and a top-down organization. We thus pose that, while both groups of new insurers reinvent the meaning of solidarity by using direct risk-sharing groups (as is central to the concept of mutuals), they have different projected development paths-especially considering how, in case of further growth, they deal with problems of moral hazard and adverse selection.
\end{abstract}

\section{Keywords}

collective action; institutions; insurance; mutualism; resilience; risk-sharing; solidarity; welfare state

Issue

This article is part of the issue "Institutions of Inclusion and Exclusion" edited by J. Cok Vrooman (Utrecht University and The Netherlands Institute for Social Research|SCP, the Netherlands) and Marcel Coenders (Utrecht University and The Netherlands Institute for Social Research |SCP, the Netherlands).

(C) 2020 by the authors; licensee Cogitatio (Lisbon, Portugal). This article is licensed under a Creative Commons Attribution 4.0 International License (CC BY).

\section{Introduction}

Be it in the fields of climate and energy, health care and welfare states, politics and governance, or banking and insurance, when it comes to solving collective problems, the shortcomings of market and state have increasingly come to light. Over the past two decades, this has sparked a revival in collective action in many countries globally, displayed by the rapid increase in the number of cooperatives in agriculture, energy, and infrastructure. People are joining forces to establish and strengthen institutions for collective action (ICAs) to solve problems that have not been solved to their satisfaction by traditional suppliers (De Moor, 2015).

Parallel to this development in collective resource management, similar developments in the service sector can be noted, particularly in insurance, where new initiatives such as Friendsurance (Germany), Broodfonds (the Netherlands), and Lemonade (US) emerged out of a mounting discontent with the way insurance is currently organized. These insurance organizations, many of which refer to themselves as peer-to-peer (P2P) insurance, aim to reinstate fair, transparent, and social insurance. Although their name suggests a one-on-one relationship 
between those involved, in practice they go back to mutual insurance principles as laid down centuries ago, pooling premiums in (small) risk-sharing pools that introduce many-to-many relationships between members.

Historically, the earliest mutual insurance associations (mutuals) can be traced back to the guilds in the first wave of collective action in early modern times (1500-1800), but the current initiatives emulate the mutuals that emerged over the 19th century during the second wave of collective action, with its culmination in 1880-1920 (De Moor, 2015). Friendsurance (Germany), for instance, evokes villagers that established mutual risksharing arrangements in the event of fire, where neighbors would help build a new home, while Axieme (Italy) takes the fishermen and ship owners that helped each other by putting money in a common treasury for boat repairs as its example. That they do not refer to the earlier guild insurance is because the 19th-century mutuals usually focused on insurance services only, whereas guilds formed multi-purpose organizations in which insurance was part of a larger package of collective services (van Gerwen \& van Leeuwen, 2000).

Following their 19th-century counterparts, we observe that the new initiatives generally base their insurance model on four principles: solidarity, transparency, fairness, and innovation. Solidarity is invoked by relying on risk-sharing in subgroups, with policyholders supporting each other with money from a common fund. Transparency is achieved by abandoning the large bureaucratic systems and making do with minimum sets of rules and clarity about insurance eligibility and payouts. Fairness is implemented by returning (some share of) unused premiums to the policyholder rather than to the insurer's profit. Innovation, finally, is where the new initiatives move beyond the historical model. Based on the assumption that 21st-century InsurTech (e.g., online exchange platforms, artificial intelligence, blockchain) has a primarily positive impact on collective action, they apply this to create large solidarity networks in our current societies.

With this article, we aim to provide a better understanding of why these new initiatives are emerging, and in so many different countries. What needs do they respond to? Do they represent a revival of mutualism or is this an entirely new institutional development? Can we expect these initiatives to play a role in the insurance sector of the future? With the 'oldest' initiative established in 2006, there is little experience to base such predictions on. However, we do have a wealth of knowledge on the development of mutuals in the past. By comparing characteristics of mutuals past and present as well as contextual developments leading to their rise (and demise), we aim to provide preliminary insights into the role these new initiatives play in our current societies, their future chances, and what factors appear crucial for their resilience.

A historical outlook is particularly helpful in reference to classic insurance problems of moral hazard and adverse selection. Moral hazard occurs when insured people increase risky behavior or decrease loss prevention (ex ante moral hazard; Arrow, 1971) or file exaggerated or even fraudulent insurance claims (ex post moral hazard; Adams, Andersson, Jia, \& Lindmark, 2011). Adverse selection occurs when insurances attract an above-average number of high-risk members (Akerlof, 1970). The general consensus is that historically, mutuals were better able to deal with these problems than early market and government insurers (Emery \& Emery, 1999; Harris, 2012). The ascribed reasons (social control, fairness, solidarity) are what the new initiatives likewise use as arguments for their case. While it is too early to state whether they succeeded in this mission, we can compare whether they are likely or certain to get into trouble due to their institutional structure.

For this purpose, we compare eleven insurance initiatives (currently) active in twelve countries, established between 2006-2018, on the basis of their institutional, resource, and user properties, which are derived from De Moor's (2015) three-dimensional model of resilience in ICAs. First, however, we lay the contextual groundwork by sketching the relevant wider economic, societal, and institutional embeddedness of these initiatives. Why are they emerging now? What pressing issues in the insurance sector are they responding to? Similarly, we provide a general outline of the historical development of mutuals. Only in comparison can we start to understand which role the new initiatives, still in their infancy, may take in our future societies.

\section{The Wider Insurance Landscape}

\subsection{The Crisis of the Insurance System}

When it comes to national insurance systems, countries have traditionally been categorized as utilizing private (US), public (Norway, Sweden, Finland, Denmark, UK, Italy, Canada), or mixed (Germany, France, Austria, Switzerland, Belgium, the Netherlands) models for organizing insurance (Lameire, Joffe, \& Wiedemann, 1999). This classification marks how the majority of insurance is organized; all countries with established insurance systems at least offer some form of public insurance-particularly for unemployment, disability, and retirement-for some subgroups (e.g., Medicaid in the US). Private insurers, however, are quickly gaining ground in all (particularly European) countries, as principles of neoliberalism have provided the economic justification for delegating the provision of social insurance (like health insurance) to private insurers (Natalier \& Willis, 2008). While this process might seem more apparent in 'mixed insurance' countries, it is also taking place in countries (such as Sweden) that have traditionally been characterized as public (Sunesson et al., 1998).

At the same time, little has been done to accommodate new risks introduced by recent demographic transitions. Aging populations (longer retirement, elderly 
care), higher divorce rates (child support), and increasing unemployment put pressure on the capacity of the welfare state (de Vroom \& Øverbye, 2017; Parkinson, 2011). Moreover, while universalist benefits are, in principle, at everyone's disposal, their implementation increasingly causes social exclusion. Eligibility is dependent on citizenship and salaried employment, which conflicts with changing demographic profiles of a globalized world (Taylor-Gooby, 2006). The condition of citizenship, for one, excludes the growing number of (labor) migrants from social benefits in most European countries (Baldini, Gallo, Reverberi, \& Trapani, 2016; Lehtonen \& Liukko, 2015): While there are large differences between European countries in the extent of exclusion, with exclusion in most Mediterranean countries double or triple the size of that in Scandinavian countries, exclusion is substantial everywhere (Baldini et al., 2016). The condition of salaried employment, secondly, deprives the growing number of self-employed workers of benefits, leaving them uninsured or at the mercy of private insurance companies (van der Linden, 2008).

These private insurers introduce increasingly detailed forms of risk segmentation by unpooling risks (Ericson, Barry, \& Doyle, 2000). While based on principles of actuarial fairness (i.e., you pay according to your needs), this mainly serves to increase profit. The repercussions of such differentiation are that premiums have become increasingly expensive for high-risk groups, if they are accepted as clients at all. Hence, the groups of people that are excluded from insurance expand, and those who do have insurance report lower levels of trust in their insurer (Lehtonen \& Liukko, 2015).

The new insurance initiatives, therefore, respond to problems with both state and private insurance arrangements. By borrowing aspects of historical mutualism, they believe they can reshape expectations of insurance and alleviate some of the financial pressures that make the benefits offered by existing parties so expensive (or unaffordable).

\subsection{A Historical Mutual Insurance Framework}

Risk-sharing through mutual insurance has been around for so long that to summarize it in a few paragraphs is impossible within the limits of this article. For excellent discussions of mutuals throughout history, we refer the interested reader to the book of van Leeuwen (2016). For this article, which puts new mutuals central, a basic overview suffices.

The mutuals that emerged in the early 19th century were the product of age-old mutually dependent social relations that took shape in local guilds and credit economies (Ismay, 2015). These mutuals arose in many different countries, but scholarly discussions largely focus on mutuals in Europe (e.g., the UK, the Netherlands, Spain), the US, and Australia (Downing, 2012; Harris, 2012). In these discussions, scholars often distinguish between mutuals that covered life risks (e.g., health, fu- neral) and non-life risks (e.g., fire, agriculture). While membership figures tentatively suggest that risk-sharing groups in the latter were smaller (van Gerwen \& van Leeuwen, 2000; also according to the authors, at least for the Netherlands, membership figures suggest that, in general, non-life mutuals had less than 100 members, while the majority of life mutuals had fewer than 500 members), the general consensus is that all early mutuals had relatively small risk-sharing pools, which gave them a comparative advantage over early market or government insurers in dealing with problems of adverse selection and moral hazard (both ex ante and ex post), as signaled by the lower number of claims (Adams et al., 2011; Emery \& Emery, 1999; Harris, 2012; van Leeuwen, 2016).

The risk-sharing groups were usually composed of people who lived in the same community, so they could vouch for each other and monitor each other's behavior (van Gerwen \& van Leeuwen, 2000). This reduced problems of adverse selection, as they had a rough estimate of the type of risk admitted in the pool. Once admitted, members were expected to take on some responsibility in governance and to participate in social events (Downing, 2012). Thus, traditional mutualism consisted not only of voluntary arrangements to contribute to a common fund (de Swaan \& van der Linden, 2006, p. 184), but served social needs as well (Harris, 2012, pp. 1-2). The social bonds and affinity that were created this way kept occurrences of moral hazard low, as it felt wrong to most people to take (excessive amounts of) money from their fellow group members. Moreover, informal monitoring and social punishments (e.g., loss of reputation) scared off those who might have still been inclined to do so.

As the 20th century approached, the membership figures of mutuals grew quickly. This increased organizational complexity, which in many cases meant that traditional ownership structures were modified to ease decision-making and minimize potential conflicts. Ultimately, this often entailed a transition towards managerial and corporate governance models, in which the management was in the hands of a managerial board consisting of external professionals. In most organizations, members only retained-to some degree-ex post decision control (Chaddad \& Iliopoulos, 2013). Moreover, despite the fact that the large mutuals were initially often structured like umbrella organizations, with members still subdivided within multiple, relatively small risksharing groups, conviviality within these groups quickly waned, which reduced their ability to monitor each other (Downing, 2012).

Essentially, this means that mutual insurance had a different definition in the early 1800 s than it does today, and this is a consequence of the evolution mutuals have gone through over the past two centuries. Nowadays it is usually the large, private, not-for-profit insurance companies (such as the US-based Liberty Mutual Group) that come to mind (de Swaan \& van der Linden, 2006, p. 12). Many of these companies evolved from 19th-century 
small-scale mutuals (van Leeuwen, 2016). ${ }^{1}$ Their defining characteristic still is that they are (partly) owned by their stakeholders and have-at least on paper-a responsibility to them for their operations (Lehtonen \& Liukko, 2015). Members are, for instance, given the right to select management, and any profit should either go to them or into the company. This is in contrast to stock insurers, which are owned by shareholders and usually see the production of wealth for shareholders as their primary function (Cummins, Weiss, \& Zi, 1999). However, while ownership has always been central to mutual insurance, the actual voice members have in organizational matters has decreased to such a degree that nowadays it is largely void of meaning (Chaddad \& lliopoulos, 2013). Moreover, the meaning of solidarity gradually changed in the evolution of mutual insurance companies. Largescale anonymous structures have come to replace the old systems, which were smaller and more focused on direct solidarity.

It is the traditional conception of mutual insurance that fits well with the new insurance initiatives. They, too, revert to subdividing the member-base into smaller risksharing groups, thereby promoting solidarity and giving the policyholders, to varying degrees, a say in the design of the institution (albeit not necessarily through ownership). Hence, while they explicitly present themselves as different from mutual insurance companies, which they treat on a par with stock insurers, the term 'peer-to-peer' might mainly be a modern rebranding of the age-old principle of mutualism.

Essentially, while for mutual insurance companies the defining feature that survived over time is formal ownership by immediate stakeholders (and by extension that profits are retained within the company), the new initiatives borrow solidarity-related aspects (risk-sharing groups, redistribution mechanisms) from the historical model that they consider apt for reducing moral hazard. A cautionary note is in place here, for although these aspects indeed made many historical mutuals successful, the same reliance on small groups and informal social control imposed fragility. If moral hazard did occur undetected, for small mutuals it more often led to financial problems or even bankruptcy (de Swaan \& van der Linden, 2006; van Leeuwen, 2016). Larger market insurers might have had more moral hazard occurrences, but also had the financial stability to cope with them.

\section{Theory}

A comparison of the new insurance initiatives requires a common framework. The initiatives in different countries largely developed independently, so such a framework helps to pinpoint differences and (particularly) similarities that may not be obvious at first. For this purpose, we apply the three-dimensional framework of De Moor (2015), originally developed for historical analysis of the functioning of commons and other ICAs, to mutuals. We see structural similarities between mutuals and ICAs, so this framework can reveal where the institutions are more fragile. The framework poses that three dimensions should be considered when evaluating cooperation for the production, use, and management of a collective good: the resource, the users, and the institution. Applied to mutuals, these reflect the insurance pool, the policyholders, and the mutual. These dimensions are tightly interrelated and resilient cooperation is the result of striking a proper balance between them.

The institution entails the overarching organizational form as well as all rules and regulations regarding both user and resource. The resource dimension encompasses everything related to the construction and use of the resource, i.e., the premiums (that together form the insurance pool) and insurance payouts. Finally, the user dimension concerns who makes up the member-base, i.e., whether the group is open or closed, small or large, homogeneous or heterogeneous. There are myriad interrelations between these dimensions: Group characteristics follow from institutional rules of entrance; resource characteristics are the result of institutional rules and users' demands and needs; resource and institutional characteristics influence which users join, and so forth. These interrelations are captured by the balance in efficiency, utility, and equity (Figure 1).

Since insurance primarily serves to protect against financial loss, efficiency is often the main balance considered. Literature that disputes the premises of the tragedy of the commons (Hardin, 1968) stresses that institutions, with properly defined rules and norms, are vital to avoiding overuse and thus to not overriding the resource's carrying capacity. Efficiency then results from the interaction between institution and resource, as the institution sets the rules of access and use that largely determine resource availability (Ostrom, 2005). For mutuals, these rules arrange financial matters of creating the fund (e.g., setting premium levels) and payout from the fund (e.g., determining coverage and eligibility). They should ensure that no more is claimed than is saved in the pool, but should simultaneously avoid underuse. When more is saved than is needed for payouts, premiums are too high and the balance is likewise inefficient. For historical mutuals, efficiency clearly improved over time. Initially there was little knowledge on how many claims should be expected, what contribution rates were necessary to cover those claims, and how eligibility should be judged. Over time, the mutuals started to professionalize by applying basic risk differentiations on crude categories of, for instance, age. Current mutual insurance companies maximize efficiency by using complex tools to calculate

\footnotetext{
${ }^{1}$ This is not to say that all 19th-century mutuals grew into large mutual insurance corporations. In fact, only a minority (mainly those that merged and professionalized) survived. Following intensifying public debates over what voluntary mutuals lacked (e.g., no coverage of prime risks like old age and industrial accidents), the vast majority were taken over by the welfare state (which would cover a broader variety of risks). Others, particularly in the non-life domain, ultimately, had to cease operations in competition with commercial insurers (van Leeuwen, 2016).
} 


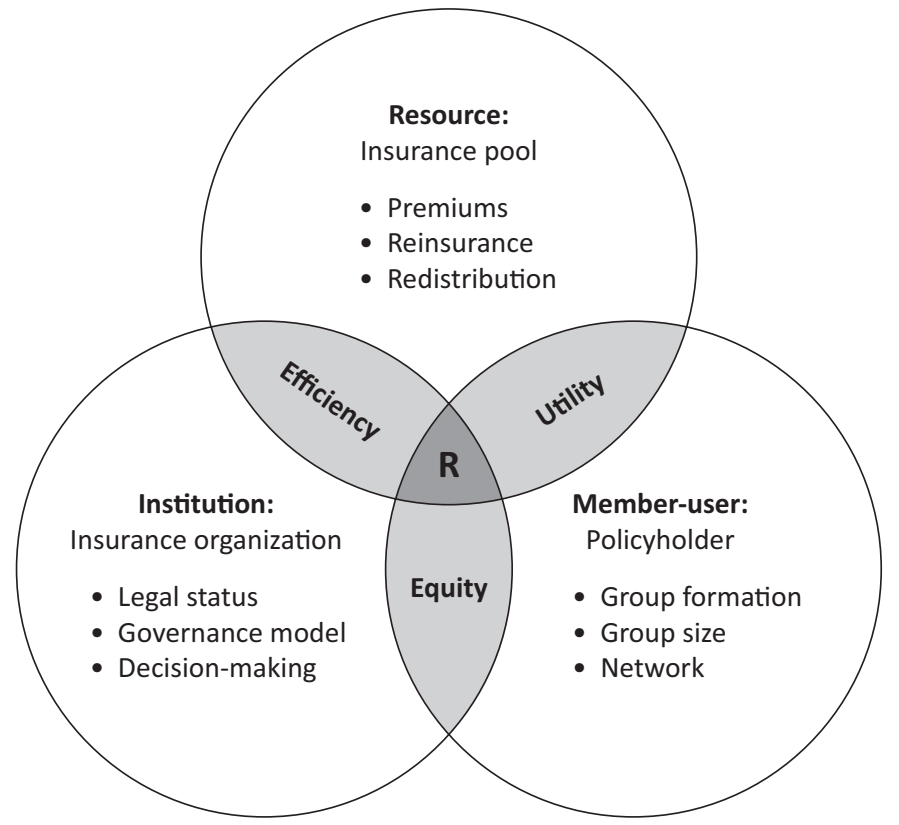

Figure 1. A three-factor approach to the functioning of mutuals, adapted from De Moor (2015). Note: R stands for Resilience.

individual risk probabilities and adjusting premiums accordingly. Moreover, they reinsure part of the premiums with external insurance companies who pay the insurance if the local pool were still to be depleted.

In addition to financial performance, social aspects form important indicators for the functioning of mutuals and other ICAs. In the framework, this is captured in the evaluation of utility and equity. Utility represents the balance between users and resource. Rather than assessing resource management, utility asks whether the resource is sufficient for the users' needs. For the historical mutuals, utility was achieved by combining various types of support. While it is true that initially payout was usually limited (both in amount and duration), being able to receive some benefits did alleviate members' most urgent needs (Emery \& Emery, 1999; Harris, 2012). Moreover, while coverage was not guaranteed, this was compensated for with additional services (e.g., social support). Over time, financially utility improved as payouts got higher and more secure, but the utility derived from social functions decreased. Moreover, while the introduction of risk differentiation may have been positive for low-risk groups, for others it meant that insurance became more expensive. In other words, utility may be perceived in different ways and vary among members within a mutual group.

Lastly, equity is achieved when users feel heard. It has long been recognized that ICAs in which members participate in the decision-making process are more likely to survive because involvement enhances reciprocity and solidarity (Ostrom, 1990). It bestows feelings of responsibility in members and makes them committed to the institution's success. Moreover, institutions characterized by member involvement appear more resilient as they are better capable of change than those gov- erned top down (De Moor, 2015), most likely because involved members better understand why, and which, changes are needed. For historical mutuals, equity was initially given a key role (through bottom-up organization and decision-making). Over time, it seems that improvements in efficiency have come at the expense of equity, as these changes were set in motion by professional board members or external managers.

In general, resilient institutions manage to balance equity, efficiency, and utility. In practice, however, balance is often achieved on two of these at the expense of the third (De Moor, 2015). For the historical mutuals, for instance, equity and utility seemed to have come at the expense of efficiency in the early 19th century, while efficiency replaced equity throughout the 20th century. We assess such matters for the new initiatives as well. By comparing the new insurance alternatives on the use of risk differentiation, reinsurance methods, and strategies for profit (i.e., characteristics of the resource and the institution) we assess their balance regarding efficiency. Risk differentiation and redistribution policies (part of the fairness goal of all initiatives) will be used as indicators for how the initiatives work towards utility. Finally, how governance decisions are made and whether policyholders have a say in drafting their rules help us assess the role they give to equity.

\section{Methods}

The number of new mutual-like organizations is rapidly increasing, although most are (still) small in size. Moreover, while they use digital tools for their organization, most still focus on local (national) markets, communicating in their respective languages, which makes it difficult to get a count of the number of active initiatives. Our in- 
ventory of new insurance initiatives was based on mentions in blogs and news reports as well as presence on social media (Twitter/Facebook). For this purpose, we used the search terms 'peer-to-peer OR P2P OR crowdsurance OR new' and 'mutuals OR mutualism OR insurance.'

We inventoried 57 initiatives (active and inactive, see Tables $A 1$ and $A 2$ in the Supplementary File) that were established between 2006-2018, with the majority (39) founded in 2015 or later. With the exception of Latin America and most of Africa-where local microinsurances are ubiquitous, but no accounts of institutionalized and digitalized initiatives were found, possibly because their insurance sectors are less developed generally and internet penetration rates are low(er)comparable initiatives are being established everywhere. The majority are European, although some of the pioneers started outside of Europe (e.g., TongJuBao in China, PeerCover in New Zealand) and several initiatives (e.g., Teambrella, VouchForMe, WorldCover) ignore national borders altogether.

Of the 57 initiatives, we selected 11 for a more thorough review (Table 1), simply because we could collect sufficient information about them. For the others, websites provided too little information, content was only available in foreign languages, and/or we could not get in touch with a representative of the organization. The selected initiatives cover different parts of the world as well as different insurance products. Still, we note that caution is warranted in contemplating these initiatives' success, as most new mutuals, with the exception of Friendsurance ( $\sim 150,000$ policyholders) and Lemonade $(\sim 425,000)$, have a relatively small member-base (with Versicherix not even officially launched yet).

\subsection{Measures}

To compare the institution, resource, and user dimensions of the insurance organizations, we derive two or three characteristics per dimension. For the institution, we compare whether the initiatives use non-profit (e.g., cooperative, association) or for-profit (stock insurance) organizational forms and to what extent users are involved in decision-making. For the resource dimension, we outline whether the initiatives use risk-differentiation and reinsurance and what share of the premium they potentially redistribute over the users. The user dimension, finally, is characterized by outlining whether the initiatives set limits to group size and whether the initiatives devise and promote means of communication among members.

\section{Results}

\subsection{Basic Characteristics}

Table 1 signals that the new initiatives offer a broad range of insurance, both in the life and non-life domain. Particularly noteworthy is that several explicitly state that they insure everything, including what is not insured by other insurers or the welfare state (e.g., pet or family insurance). Sometimes this alternative insurance offer is how they market themselves (e.g., the family insurance of TongJuBao). Others merely create the platform and invite (groups of) people to use this platform for any insurance they have in mind (e.g., Besure).

In the non-life domain, there is an emphasis on insurance types that enable some form of standardized risk differentiation and have relatively stable, mostly one-off insurance payouts (e.g., motor, pet, or travel insurance). These insurance types may be particularly suitable for mutual insurance, because they lower the uncertainty with respect to how much insurance is needed when claims are filed and for how long.

In the life domain, most mutuals historically focused on burial insurance, because all members need it at some point and moral hazard will be limited. When health insurance was offered, this was made feasible through minimal coverage that was capped at a limited number of consecutive months (van Leeuwen, 2016). We see this strategy in use again for the new insurance types that insure health or disability. These organizations are a direct response to the privatization of insurance that was previously offered by the welfare state. Broodfonds, for instance, started after the Dutch state abolished the Disability Act for self-employed workers in 2004. With this abolishment, the Netherlands no longer offered social security arrangements for self-employed workers to cover sickness and disability. Instead of taking out a disability insurance with a private insurance company (which for most self-employed workers is too expensive), the Broodfonds emerged as a cheaper and social alternative. The insurance provided is usually only a minimum income replacement and for a certain number of months (e.g., two years for the Dutch Broodfonds). This way, they make insuring more unpredictable risks manageable.

\subsection{Institutional, Resource, and User Features}

Before reflecting on overall balance, we outline the main institutional, resource, and user features, categorizing the initiatives based on two or three characteristics. For more detailed information per initiative, we refer the reader to Tables A3-A5 in the Supplementary File.

With regard to the institution, a dichotomy arises when we compare the initiatives based on their organizational form and decision-making structure (Table 2). All top-down-organized initiatives are start-ups by entrepreneurs wishing to disrupt the insurance sector with a model that, institutionally, maintains the standard, forprofit structure (albeit as social enterprise in the case of SharePeople), but introduces innovations mainly in user and resource characteristics. Initiatives with bottom-up structures, on the contrary, started as local solutions that later scaled to associations or cooperatives (e.g., Broodfonds, CommonEasy) or were designed within the platform-economy movement before looking for users 
Table 1. Overview of new mutuals included in review, sorted by founding year.

\begin{tabular}{|c|c|c|c|c|}
\hline P2P insurer & $\begin{array}{l}\text { Year (founded) } \\
* \text { launched }\end{array}$ & Country & \# Policy-holders & Type of insurance \\
\hline Broodfonds & (2006) 2011 & Netherlands & $>20,000$ & $\begin{array}{l}\text { Life: Income protection for self-employed } \\
\text { workers }\end{array}$ \\
\hline Friendsurance & 2010 & Germany, Australia & $\sim 150,000$ & $\begin{array}{l}\text { Non-life: Deductibles of insurance offered } \\
\text { by } 175 \text { insurance partners (e.g., household, } \\
\text { liability, motor) }\end{array}$ \\
\hline CommonEasy & (2014) 2016 & Netherlands & $<1,000$ & $\begin{array}{l}\text { Life: Income protection for self-employed } \\
\text { workers }\end{array}$ \\
\hline TongJuBao & 2014 & China ** & $>20,000$ & $\begin{array}{l}\text { Life: Divorce; child abduction; family } \\
\text { migration }\end{array}$ \\
\hline Lemonade & (2015) 2016 & US & $\sim 425,000$ & Non-life: Renters'; home \\
\hline Teambrella & 2015 & International $* * *$ & $<500$ & Non-life: Motor; bicycles; pets \\
\hline Versicherix & (2015) & Switzerland & 0 & Anything policyholders need insured \\
\hline Axieme & 2016 & Italy & $>2,000$ & $\begin{array}{l}\text { Anything policyholders need insured (e.g., } \\
\text { professional risk; casualty \& property) }\end{array}$ \\
\hline Besure & 2016 & Canada & Not disclosed & Anything policyholders need insured \\
\hline Tribe & 2016 & Norway & $>2,500$ & $\begin{array}{l}\text { Non-life: House; furniture; motor; health; } \\
\text { travel; pets }\end{array}$ \\
\hline SharePeople & 2017 & Netherlands & $<1,000$ & $\begin{array}{l}\text { Life: Income protection for self-employed } \\
\text { workers }\end{array}$ \\
\hline
\end{tabular}

Notes: ${ }^{*}$ Added only if the launch year differs from the founding year; ${ }^{* *}$ TongJuBao is looking for a market in Europe and the US under the name P2P Connect; ${ }^{* * *}$ Teambrella is currently active in Argentina, Germany, Peru, Russia, the Netherlands, and the US.

that would shape the actual rules of governance (e.g., Besure, Teambrella). These initiatives make the users responsible by involving them in the design of operational rules.

Roughly the same categories apply for the resource characteristics. The top-down insurers use InsurTech technologies to calculate individual risk profiles, which are refined over time and translate into highly differentiated premium levels. Moreover, they cooperate with established insurers to guarantee payout when the local insurance pool is exhausted (Table 3). This is how they claim to provide high utility for everyone, but for low-risk groups in particular (for whom extensive risk differentiation should generate lower premiums than with regular insurers).
The bottom-up initiatives start instead from the premises of equality and inclusion and do not differentiate based on (in their opinion) subjective risk profiles. To keep premiums low, their payouts usually do not provide full coverage; instead, they primarily want to make minimal support available to everyone. Therefore, they do not cooperate with established insurers for external reinsurance either. The larger (and older) initiatives (Broodfonds and TongJuBao) do have internal reinsurance systems that operate across the risk-sharing groups, but initially all mutuals in this category pose the basic risk that payouts are not guaranteed: If the pool is depleted, losses are not covered.

A resource characteristic that distinguishes all new initiatives from regular insurers is their use of redistribu-

Table 2. Categorization based on organizational form and decision-making structure.

\begin{tabular}{lccc}
\hline & & Organizational form \\
\cline { 2 - 3 } & & \multicolumn{1}{c}{ For-profit, stock } & $\begin{array}{c}\text { Social enterprise, association, } \\
\text { (platform) cooperative }\end{array}$ \\
\hline \multirow{3}{*}{ Decision-making } & Provider & $\begin{array}{l}\text { Axieme, Friendsurance, Lemonade, } \\
\text { Tribe, Versicherix }\end{array}$ & SharePeople \\
\cline { 2 - 3 } & Both & & Broodfonds, CommonEasy, TongJuBao \\
\cline { 2 - 3 } & User & Besure, Teambrella \\
\hline
\end{tabular}


Table 3. Categorization based on risk differentiation and reinsurance policies.

\begin{tabular}{|c|c|c|c|}
\hline & & \multicolumn{2}{|c|}{ Risk differentiation } \\
\hline & & Yes & No \\
\hline \multirow{3}{*}{ Reinsurance } & External & $\begin{array}{l}\text { Axieme } * \text {, Friendsurance, Lemonade } * * \\
\text { Tribe, Versicherix }\end{array}$ & \\
\hline & Internal & Lemonade $^{2}$ & Broodfonds, TongJuBao \\
\hline & None & & Besure, CommonEasy, SharePeople, Teambrella \\
\hline
\end{tabular}

Notes: * Axieme, Friendsurance, and Tribe act as brokers so reinsurance is arranged by the insurance carrier they connect the policyholder to; ${ }^{* *}$ Lemonade uses external reinsurance as backup for internal reinsurance.

tion policies. Based on a fairness notion that premiums contributed to the pool are only meant for insurance payouts, all initiatives return at least some share of the unused premiums at the end of the term (usually one year). While we do observe that the maximum redistribution share is lower for the for-profit initiatives (which also invest part of the premium in external reinsurance), the share is substantial everywhere (Figure 2).

For member characteristics, finally, we find that communication within risk-sharing groups is possible (and stimulated) only in the bottom-up mutuals (Table 4), who base this on the idea that communication fosters commitment directly by creating agreement on rules and payouts, and indirectly by fostering cohesion and solidarity. However, when we divide the initiatives based on whether or not they pose restrictions on the maximum size of risk-sharing groups, the resulting division cannot be explained. The initiatives that pose such restrictions are Besure (which compels groups to set limits, but gives them freedom to decide on these limits), Broodfonds (20-50 members), Friendsurance (exactly 10), and Tribe (at most 10).
While the chosen limits vary per initiative, they are implemented out of a belief that the number of people towards which solidarity can be invoked is limited. When group members are anonymous or when groups exceed a boundary beyond which social norms can no longer be maintained, risk-sharing is no longer believed to reduce moral hazard. The other initiatives, contrarily, believe in the strength of large numbers and argue that solidarity is not directed towards specific others but generalized to the group as a whole. This is an interesting discord, as there is no agreement on optimal group size in research on ICAs either. Collective action is argued to benefit from larger groups, as it allows for a better spreading of risks, but larger groups are also considered detrimental for cohesion and therefore the willingness to cooperate (Olson, 1965; Poteete \& Ostrom, 2004). We return to this issue in the discussion.

\subsection{The Balance on Efficiency, Utility, and Equity}

Apart from the ambiguity regarding group size, the new initiatives can be conceptualized as falling into two cate-

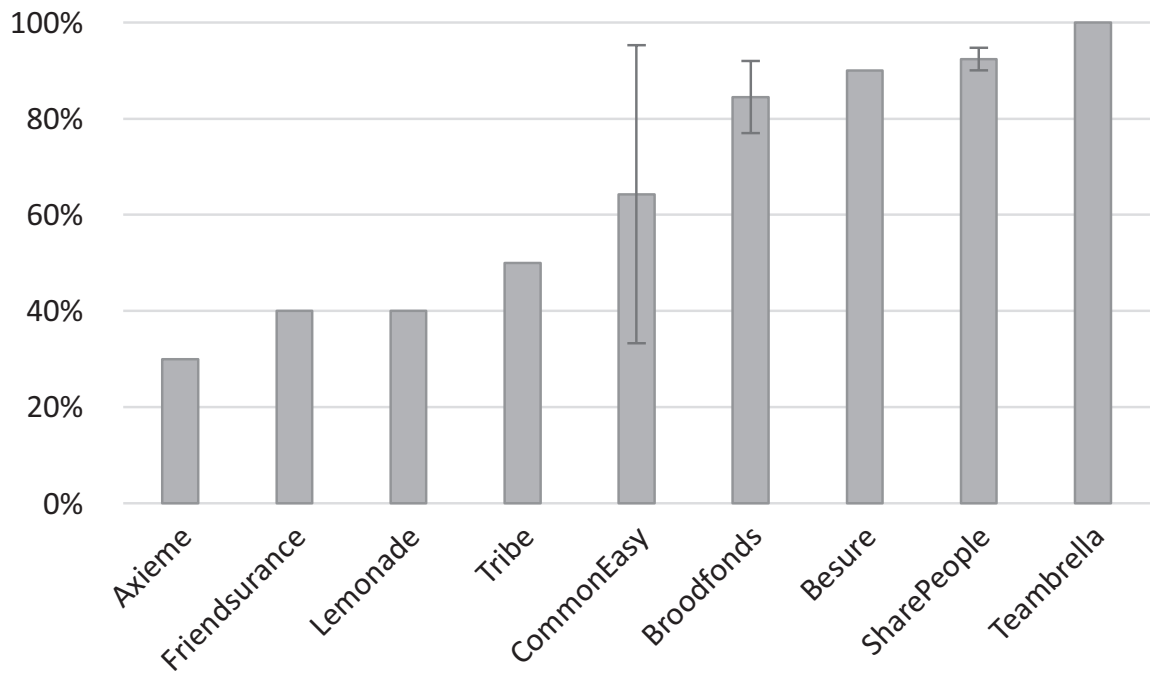

Figure 2. Maximum premium redistribution per organization. Notes: Information is missing for TongJuBao and Versicherix; the redistribution percentage for CommonEasy, Broodfonds, and SharePeople fluctuates because the amount unavailable for redistribution is a fixed (absolute) fee regardless of the premium level. See Table A6 in the Supplementary File for calculations. 
Table 4. Categorization based on communication and group size configurations.

\begin{tabular}{llll}
\hline \multirow{2}{*}{ Group size restrictions } & & \multicolumn{2}{c}{ Communication among users } \\
\cline { 2 - 4 } & Yes & Besure, Broodfonds & No \\
\cline { 2 - 4 } & No & CommonEasy, Teambrella & Axieme, Lemonade, SharePeople \\
\hline
\end{tabular}

Notes: Information on Versicherix is missing; members of Tribe do group with members they already know, so they likely do communicate via other means, but this is not structured through (or stimulated by) the mutual.

gories. The top-down organizations use risk-sharing and redistribution as innovative tools, but institutionally they resemble modern market insurance structures, while the bottom-up organizations largely resemble their 19thcentury counterparts-including the fact that they cannot promise the same degree of security as regular insurance companies do. Organizations of the latter type therefore unmistakably represent a revival of mutualism, operating between market and state, while the first category might be better classified as a new alternative within the market insurance sector.

The difference in how the two categories balance on efficiency, utility, and equity makes clear why. First, the dichotomy translates into a different vision of utility. While organizations in both groups emerged to better answer to policyholders' needs (i.e., the utility domain) than their state or market counterparts, they differ in how they perceive these needs. The top-down organizations envision optimal utility in an insurance policy that most accurately reflects actual needs (i.e., with premiums that most meticulously represent actual risk profiles). With this vision they aim particularly to improve utility for low-risk members. The bottom-up organizations consider utility to reflect a minimum security level for everyone, including high-risk individuals that may have difficulty taking out an insurance policy with private insurers. Whether this vision fits everyone's needs or ultimately results in problems of adverse selection (i.e., risksharing groups with an above-average number of highrisk members; Akerlof, 1970) remains to be seen.

The implementation of utility is thus unevenly balanced towards different target users, but at least improving utility constitutes a core concern for all new insurance initiatives. An assessment of the balance in efficiency and equity, however, signals the clear division between the two types of organizations. Typically, topdown organizations strive for utility and efficiency at the expense of equity, while the bottom-up organizations strive for utility and equity at the expense of efficiency (Figure 3). That is, the first group organizes the risk-sharing groups such that exactly the right amount of premiums is paid, but can only do so by fixing the institutional setup and not giving members a say in how the group should organize itself. While this makes the pool governance and the decision-making process more efficient, the consequence of low member involvement might be that they perceive less procedural justice, e.g., on premium sizes or payout eligibility.

The second type of organization leaves much room for members to decide upon their internal structure and

\section{Top-down organizations}

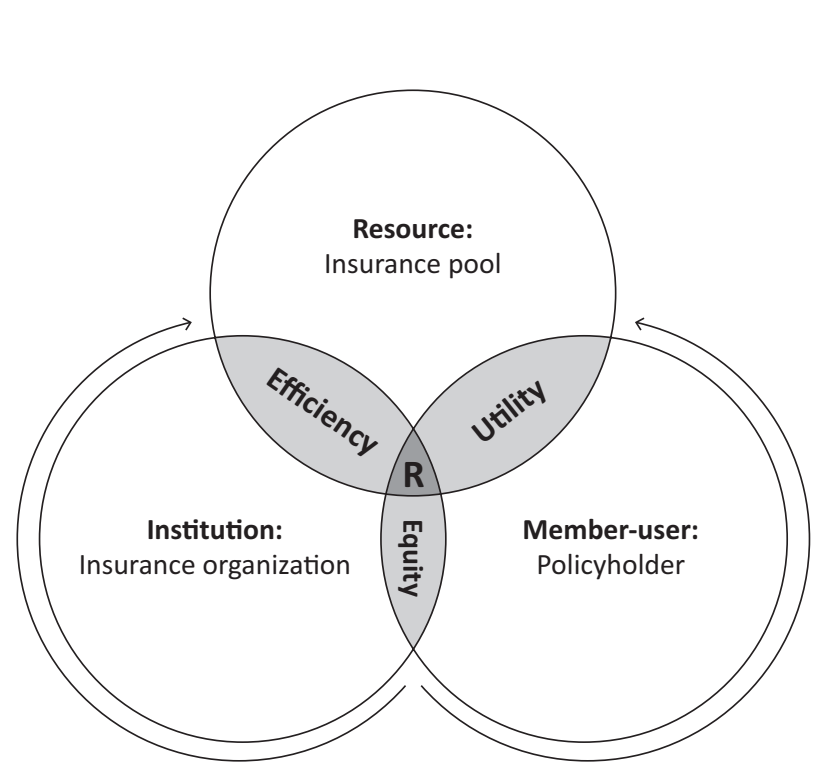

Bottom-down organizations

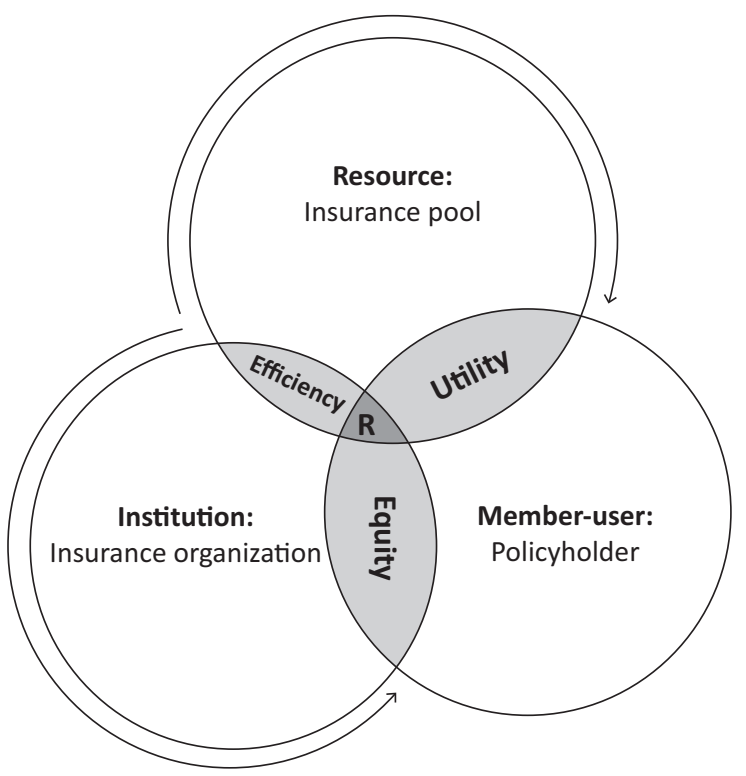

Figure 3. Balance configurations for the two types of new insurance initiatives. Note: R stands for Resilience. 
criteria for payout eligibility, which, although it enhances feelings of procedural justice, can result in a lengthier and more difficult decision-making process and less efficient management. Although with time efficiency may increase when decision-making processes have consolidated and the formation of trust has rooted within the organization (De Moor, 2015), currently both types of organizations seem to balance two dimensions at the expense of the third. If the two types of organizations continue down this road, it stands to reason that, when they do grow up to be solid insurance alternatives, these initial differences will become more marked.

When we consider the number of members as a first indicator, for instance, it should be noted that some of the top-down organizations (Friendsurance, Lemonade) have larger member-bases than the bottom-up mutuals. This is without doubt related to the fact that topdown structures make it easier for members to sign up. New members are not responsible for creating a risksharing group with all corresponding institutional demands, whereas in bottom-up organizations they first have to find sufficient interested others to form a pool with, and subsequently have to reach agreement on how they want to organize cooperation. Even when new risksharing groups can start from some basic institutional framework, this may imply a higher threshold for joining. Hence, the top-down organizations are more likely to grow, and to do so more quickly, in the coming years.

At the same time, this rapid growth and lack of member involvement raises the question of how the concept of solidarity will develop and whether the top-down organizations will manage to keep their role and meaning different from those of regular insurers. Simply forming a risk-sharing group by itself may not be sufficient; social identities have to be constructed to stimulate members' willingness to help others or prevent them from filing excessive or fraudulent insurance claims (i.e., moral hazard). Without active conveyance of solidarity and helping norms, the top-down organizations could develop in the direction of regular insurers, albeit with a different internal structuring of how insurance payouts are arranged.

With regard to the bottom-up organizations, it should be noted that so far, few have managed to secure a solid position as insurance alternatives. Some have had difficulties in getting off the ground (e.g., PeerCover in New Zealand), while others (like HeyGuevara in the UK and InsPeer in France) have stopped their operations after a few years. The uncertainty that comes with these organizations (no full coverage, no payout guarantee) might be too big of a step to take for people who have gotten accustomed to the availability of insurance in the welfare state. Hence, if the bottom-up mutuals want to become serious insurance alternatives, they have to reduce this uncertainty-for instance (like Broodfonds) by creating their own reinsurance system. The crucial task here is to do so in a way that does not jeopardize the established equity. A potential pitfall of further institutionalization (and bureaucratization) is that it may come at the expense of key values like responsibility and transparency.

\section{Conclusion and Discussion}

So why, then, do we see new mutual-like organizations popping up in many different countries? What needs do they answer to and do they answer them sufficiently? How are they organized and what are the institutional parallels between these otherwise independently evolving initiatives? Can we expect these alternative organizational forms to proliferate and succeed in the long run? While the phenomenon is recent, the questions are not: They have been asked-and answered-with respect to historical mutuals as well. These mutuals emerged in the classical liberal era (early 19th century) due to inadequate public provisions with respect to, e.g., poor relief (Ilcan \& Basok, 2004). They grew in popularity quickly, succeeded in alleviating their members' immediate needs, and ensured sufficiency by offering additional immaterial (social) support (Emery \& Emery, 1999). At the same time, their voluntary organization and freedom to pose membership restrictions meant that large parts of the population were never covered by mutual insurance arrangements. In the 20th century, the mutuals' services were therefore increasingly incorporated by the state, making mutuals the founding fathers of the modern welfare state (Beito, 2000). Elsewhere, the mutuals professionalized to compete with the growing number of market insurers, trying to find a niche between market and state in which they could offer the same levels of security while maintaining their member involvement and ownership advantage (Schneiberg, 2002).

Even though the new mutuals movement is still in its infancy, we have seen that the story of their rise is unmistakably similar: to answer to the inadequate insurance provisions of market and state, this time in the neoliberal era. Will the rest of the cycle repeat as well? Although it is too early to say (we would be comparing a development of two decades to one of two centuries), our review does indicate that, already in their foundation, the new insurance organizations seem to divide themselves into a group that aims to cater particularly to the needs of high-risk individuals, thereby rethinking the conceptions of solidarity and universalism as implemented by the welfare state in the life domain, and a group that targets particularly the needs of low-risk individuals, mostly in competition with the traditional market insurers in the nonlife domain. It is therefore not unimaginable that, when the two insurance types manage to secure a solid position within the existing insurance landscape, they may likewise affect the organization of both the welfare state and market insurers.

This would, however, require that they learn from the 'mistakes' made by their historical counterparts. We have seen that while all new mutuals are attentive to ensuring utility, there is room for improvement in their balance on either equity or efficiency. If the organiza- 
tions are to follow their current development path, the top-down organizations risk ending up similar to today's mutual insurance companies, having aspects of mutual insurance on paper (in this case, risk-sharing groups), without reaping the benefits in practice. Feelings of solidarity and trust-crucial to keeping moral hazard occurrences low-may gradually be forgotten as the risksharing group becomes more abstract and anonymous. For the bottom-up organizations, on the other hand, neglecting the balance on efficiency might become problematic if mutuals encounter problems of adverse selection. Low premiums and zero-to-limited risk differentiation might, as we have also seen in the development of historical mutuals (van Leeuwen, 2016), make the new mutuals particularly attractive to high-risk individuals. Risk-sharing groups with an above-average number of high-risk members may encounter difficulties when the number of claims exceed the resource's carrying capacity. For the new insurance initiatives to become resilient, it is therefore vital that they improve their balance regarding efficiency or equity, without harming the established balance on the other dimensions too much.

In light of these conclusions, a word of caution is in order. While we have stressed repeatedly that the initiatives are still in their infancy, it should also be noted that our inventory of new mutual-type insurance initiatives is by definition incomplete. We by no means claim to have a complete overview; after all, new mutualist organizations may be being set up as we speak. Since the initiatives develop largely independently of one another, it is difficult to get a grip on the available experience, and we cannot claim that a third organizational form is not being, or will not be, developed.

Frankly, the study of the role and development of new mutualism is only just beginning. While we can learn from historical experiences, many questions remain unanswered. First, as we have already touched upon, the historical mutuals-not just those 19th-century mutuals referred to in this article, but the older forms of guild insurance as well-have also known various different development paths. Some professionalized within the bottom-up framework and, similar to Broodfonds and TongJuBao, drafted multilevel reinsurance systems to cater their insurance to more members without losing the small-group benefits of informal sanctioning and control mechanisms. Others, especially towards the 20th century, transformed into top-down organizations in order to compete with private insurers. It is to date unclear, however, why some mutuals survived while others did not. This signals that much more can be learned about institutional resilience from a direct comparison between some historical and current cases-to improve both the current institutions' resilience and the understanding of the historical mutuals' demise. Which institutional features are crucial for resilience? And which may potentially be harmful? More detailed case-by-case comparisons may yield insight into how the mutuals adjust over time and can restore their balance towards resilience.
Secondly, more insight into the role of group size and solidarity is warranted. While scholars have attempted to estimate optimal community sizes (Casari \& Tagliapietra, 2018; Dunbar \& Sosis, 2018), we know little about why certain community sizes seem to work well. What is the number of people to whom one can act on the basis of solidarity? Does solidarity even have to be directed at specific individuals or can it be generalized to a collective group identity? The mutuals that apply restrictions to group size base these restrictions on common-sense intuitions, but how accurate are these? Given that risksharing groups are the foundation of the new mutuals, but their limits range from 10 to 50 to (in theory) infinity, it is pertinent that we gain a better understanding of the relation between group size and solidarity. Do solidarity feelings increase or decrease depending on the size of the risk-sharing group? And is this relation even linear?

Finally, we know that differences in the institutional setup have important implications for individual and social factors that shape willingness to participate in mutuals. Institutions could, for instance, both enhance and crowd out solidarity motives (Bowles, 2008). To illustrate, whether or not the mutual provides an internal platform for communication matters a lot for how solidarity is perceived in practice, i.e., as generalized or the outcome of a direct interdependence between members. How do institutions shape social dynamics like a mutual sense of belonging or internal social norms? What role do such dynamics play for the willingness to participate (and more specifically, to support others)? And lastly, to what extent can digital communication platforms invoke social dynamics similar to those that work in offline, localized communities?

Further research on the interplay between institutional, social, and individual factors will enhance our understanding of the functioning of the new mutuals (and by extension other ICAs) in our current societies, and ultimately increase insights into the role such initiatives are projected to play in the future.

\section{Acknowledgments}

The authors would like to thank Marco van Leeuwen, Vincent Buskens, Jonathan Fink-Jensen, Ton Duffhues, and three anonymous reviewers for their useful comments on earlier drafts of this article. Moreover, they acknowledge that this research benefited from the support of the Netherlands Organization for Scientific Research (NWO) Talent Grant [Grant No. 406.16.527].

\section{Conflict of Interests}

The authors declare no conflict of interests.

\section{Supplementary Material}

Supplementary material for this article is available online in the format provided by the authors (unedited). 


\section{References}

Adams, M., Andersson, L.-F., Jia, J. Y., \& Lindmark, M. (2011). Mutuality as a control for information asymmetry: A historical analysis of the claims experience of mutual and stock fire insurance companies in Sweden, 1889 to 1939. Business History, 53(7), 1074-1091.

Akerlof, G. A. (1970). The market for "lemons": Quality uncertainty and the market mechanism. The Quarterly Journal of Economics, 84(3), 488-500.

Arrow, K. J. (1971). Essays in the theory of risk-bearing. Chicago, IL: Markham Publications.

Baldini, M., Gallo, G., Reverberi, M., \& Trapani, A. (2016). Social transfers and poverty in Europe: Comparing social exclusion and targeting across welfare regimes (DEMB Working Paper Series No. 91). Retrieved from https://ideas.repec.org/p/mod/depeco/0091.html

Beito, D. T. (2000). From mutual aid to the welfare state: Fraternal societies and social services, 1890-1967. Chapel Hill, NC: The University of North Carolina Press.

Bowles, S. (2008). Policies designed for self-interested citizens may undermine 'the moral sentiments': Evidence from experiments. Science, 320, 1605-1609.

Casari, M., \& Tagliapietra, C. (2018). Group size in social-ecological systems. Proceedings of the $\mathrm{Na}$ tional Academy of Sciences, 115(11), 2728-2733.

Chaddad, F., \& Iliopoulos, C. (2013). Control rights, governance, and the costs of ownership in agricultural cooperatives. Agribusiness, 29(1), 3-22.

Cummins, J. D., Weiss, M. A., \& Zi, H. (1999). Organizational form and efficiency: An analysis of stock and mutual property-liability insurers. Management Science, 45(9), 1254-1269.

De Moor, T. (2015). The dilemma of the commoners. New York, NY: Cambridge University Press.

de Swaan, A., \& van der Linden, M. (2006). Mutualist microfinance: Informal savings funds from the global periphery to the core? Amsterdam: Aksant.

de Vroom, B., \& Øverbye, E. (2017). Ageing and the transition to retirement: A comparative analysis of European welfare states. London: Routledge.

Downing, A. (2012). Social capital in decline: Friendly societies in Australia, 1850-1914. Discussion Papers in Economic and Social History, 2012(105). Retrieved from https://www.economics.ox.ac.uk/materials/ working_papers/2500/downing105.pdf

Dunbar, R. I. M., \& Sosis, R. (2018). Optimising human community sizes. Evolution and Human Behavior, 39(1), 106-111.

Emery, G. N., \& Emery, J. C. H. (1999). A young man's benefit: The Independent Order of Odd Fellows and sickness insurance in the United States and Canada, 1860-1929. Montreal: McGill-Queen's University Press.

Ericson, R., Barry, D., \& Doyle, A. (2000). The moral hazards of neo-liberalism: Lessons from the private insur- ance industry. Economy and Society, 29(4), 532-558.

Hardin, G. (1968). The tragedy of the commons. Science, 162(3859), 1243-1248.

Harris, B. (2012). Welfare and old age in Europe and North America: The development of social insurance. London: Pickering \& Chatto.

Ilcan, S., \& Basok, T. (2004). Community government: Voluntary agencies, social justice, and the responsibilization of citizens. Citizenship Studies, 8(2), 129-144.

Ismay, P. (2015). Between providence and risk: Odd fellows, benevolence and the social limits of actuarial science, 1820s-1880s. Past and Present, 226(1), 115-147.

Lameire, N., Joffe, P., \& Wiedemann, M. (1999). Healthcare systems-An international review: An overview. Nephrology Dialysis Transplantation, 14, 3-9.

Lehtonen, T. K., \& Liukko, J. (2015). Producing solidarity, inequality and exclusion through insurance. Res Publica, 21(2), 155-169.

Natalier, K., \& Willis, K. (2008). Taking responsibility or averting risk? A socio-cultural approach to risk and trust in private health insurance decisions. Health, Risk and Society, 10(4), 399-411.

Olson, M. (1965). The logic of collective action: Public goods and the theory of groups. Cambridge, MA: Harvard University Press.

Ostrom, E. (1990). Governing the commons: The evolution of institutions for collective action. Cambridge: Cambridge University Press.

Ostrom, E. (2005). Understanding institutional diversity. Princeton, NJ: Princeton University Press.

Parkinson, P. (2011). Another inconvenient truth: Fragile families and the looming financial crisis for the welfare state. Family Law Quarterly, 45(3), 329-352.

Poteete, A. R., \& Ostrom, E. (2004). Heterogeneity, group size and collective action: The role of institutions in forest management. Development and Change, 35(3), 435-461.

Schneiberg, M. (2002). Organizational heterogeneity and the production of new forms: Politics, social movements and mutal companies in American fire insurance, 1900-1930. In M. Lounsbury \& M. J. Ventresca (Eds.), Research in the sociology of organizations (pp. 39-89). Bingley: Emerald.

Sunesson, S., Blomberg, S., Edebalk, P. G., Harrysson, L., Magnusson, J., Meeuwisse, A., ... Salonen, T. (1998). The flight from universalism. European Journal of Social Work, 1(1), 19-29.

Taylor-Gooby, P. (2006). Trust, risk and health care reform. Health, Risk and Society, 8(2), 97-103.

van der Linden, M. (2008). Workers of the world: Essays toward a global labor history. Leiden: Brill.

van Gerwen, J., \& van Leeuwen, M. H. D. (2000). Zoeken naar zekerheid: Risico's, preventie, verzekeringen en andere zekerheidsregelingen in Nederland 1500-2000. Vol. I: De eenheidsstaat: Onderlinges, armenzorg en commerciële verzekeraars 1800-1890 [Searching for security: Risks, prevention, insurances, 
and other social security arrangements in the Netherlands 1500-2000. Vol. I: The unitary state: Mutuals, poor relief, and commercial insurance companies 1800-1890]. The Hague: Verbond van Verzekeraars and NEHA.

\section{About the Authors}

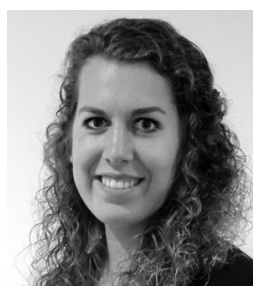

Eva Vriens (Utrecht, 1991) is a PhD Student in the Department of Sociology at Utrecht University. Her dissertation focuses on new mutualism and alternative ways of organizing insurance. Through a combination of survey methods, simulation studies, and experiments she studies the emergence and resilience of cooperation, with a particular focus on the dynamics and interdependencies of trust, solidarity, and networks of members within mutual groups.

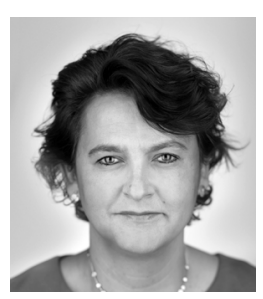

Tine De Moor (Ghent, 1975) is Full Professor in 'Institutions of Collective Action in Historical Perspective' at the Department of History and Art History of Utrecht University. Her research focuses on the emergence, functioning, and evolution of institutions for collective action; part of this research specifically focuses on citizens' collectivities, a form of collective action seems to be especially pertinent today to fill the social gaps caused by stepping-back governments and the failure of free-market mechanisms. For more info: www.collective-action.info 